\title{
UN BELLO IMPRESO DESCONOCIDO DEL SIGLO XVIII
}

\author{
Por Francisco de la Maza
}

ExIste un interesantísimo impreso poblano, estética y tipográficamente hablando, que ha sido ignorado por los bibliógrafos. $\mathrm{Y}$ no por negligencia de ellos, sino por la insigne rareza del impreso. El ejemplar que estudiamos es el de la espléndida biblioteca del señor don José Ignacio Conde, a cuya gentileza debemos el poder reseñar y dar a conocer esta obra de arte de la tipografía mexicana.

Es un memorial genealógico del canónigo licenciado don Felipe Rodríguez de Ledesma, Cornejo, Núñez de Prado y Zúñiga, quien, agradecido al rey por su nombramiento, le demuestra que no se equivocó en su persona. Pocas veces puede darse el caso, como éste, de disfrazar la vanidad con la gratitud.

Comienza: "Al Rey/Nuestro Señor/en el Real y Supremo Consejo/de Indias ofrece, insinuando la pusilidad de susjméritos, la deprecación de sus Reales memorias/el contenido en éste".

Aclaremos que "pusilidad" es un latinismo, de cierto uso entonces, que quiere decir "nimiedad", "pequeñez".

El licenciado Rodríguez de Ledesma habla sido nombrado tesorero de la Catedral de Arequipa y luego canónigo de la de Puebla de los Ángeles. Si todos los canónigos agradecieran al rey sus nombramientos con folletos como éste, las prensas coloniales mexicanas hubieran superado a las europeas. Pero nos hubieran llenado de banalidades y es mejor que este librito quede como una de las mejores obras del arte tipográfico de la Nueva España.

Prosigue el canónigo diciendo al rey que "está pronto a más graves operaciones en qué constituirse voto más grato a Vuestro Real servicio..." No cabe duda que el licenciado don Felipe Rodríguez de Ledesma quería una mitra. $Y$ se la merecia.

Mas sigamos con el impreso. A pesar de que nos importe poco su biografía, digamos algo de ella. Nació en la Villa de Béjar, territorio de Salamanca, Obispado de Plasencia. Estudió en la Universidad hasta graduarse en ambos Derechos y fue "asistente" a los cursos de Filosofía. Fue designado por el rey Carlos II, tesorero de la Catedral de Arequipa 
y luego canónigo de la de Puebla, en 1698, tomando posesión en $1700 .^{1}$ En 1705 fue elegido prepósito del oratorio de San Felipe Neri. Fundó allí la Santa Escuela de Cristo, esa Archicofradía que hizo cierto ruido y fama en su época y que se extendió luego a varias provincias de la Nueva España. Y, claro, logró recaudar algunas rentas que "la inadvertencia o el olvido tenían extinguidas", como la del ingenio de azúcar llamado "de Colón". Con ello logró el beneficio de "meter" el agua en San Felipe Neri, que antes se compraba a los aguadores ambulantes. Fue abad de la Congregación de San Pedro y "sin perjuicio de tantas obligaciones precisas, aprovecha los intervalos que puede usurparle aun a sus comodidades, ejerciendo la lección (es decir, la cátedra) y estudio de libros, en que ha empleado mucha parte de sus rentas".

Nos dice que publicó una Vida de San Felipe Neri, con el título de Lucero de Florencia, "en metro castellano, alegorizadas sus virtudes y autorizados sus conceptos con sagradas letras y trasiego de las leyes de la poesía y retórica, ejercitadas la Filosofía, Historia y Teologia". También publicó una Propugnación juridica. Ninguno de estos dos impresos es conocido tampoco. Don José Toribio Medina, en su imponente e insustituible obra $L a$ imprenta en México, señala un impreso de Rodríguez de Ledesma de 1718, un Sermón de la Soledad de Maria Santisima que en la reverente capilla de su advocación, en la Santa Iglesia Catedral de la Ciudad de los Angeles, predicó...2

Nos explica luego que tenía manuscrita una Citara Misteriosa métrica castellana en glosas de las Sentencias selectas del. Doctor Máximo San Gerónimo... y que "está poniendo en la versión y glosa del Contemptus Mundi, con adiciones de pensamientos e ilustraciones de todas letras, morales y divinas".

Tenemos, pues, un nuevo poeta novohispano desconocido.

Acaban estos méritos y servicios en el folio 7 con un escudo español grabado en madera.

Sigue luego una elaborada página tipográfica con el "Epitome/de la Accendencia y Origen Genea/lógico de el Canónigo Don Felipe/Rodríguez de Ledesma/y Cornejo Núñez de/Prado y Zúñiga", con todos esos ascendientes, desde Don Favila, duque de Cautabria, padre del rey don Pelayo, hasta el propio padre del canónigo.

1 Libro de Cabildos de la catedral de Puebla, vol 17, foja 193 vta. (Cortesía del doctor Efrain Castro.)

2 Op.cit., tomo rv, núm. 2540, pp. 20-21. 


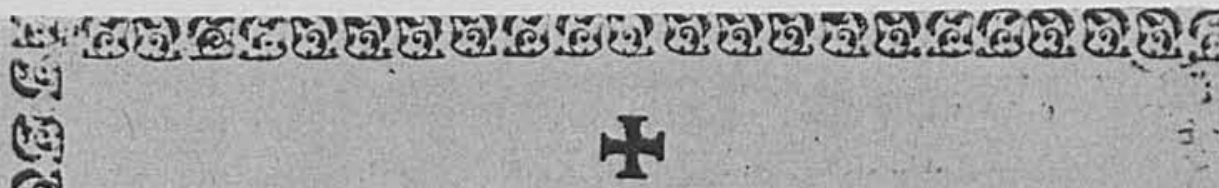

(6)
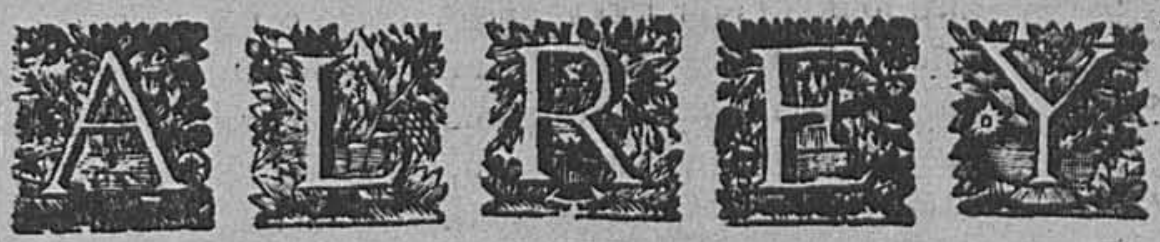

\section{NVESTROSENOR}

EN EL REAL, Y SUPREMO CONSEJO

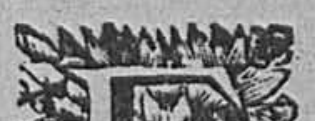

\section{LICENCIADO DON FELIPE} Rodriguez de Ledefma, Cornejo, Nuñez de Prado, y Zuniga: Canonigo de los des le ha hecho lombra à fu exaltacion, dandole cuerpo, que poftrar (avnque de lejos)à las aras, fobre que befa rendido vueftros Reales pies, en quefu plant3, fu amor, y buena ley, eftimulado (como favarecido) à la emprefa de acrecer meritos, $q$ en nuebos fervicios lo organizen imagen deV.R. foberania, empleo en que libra fu gratitud la repenfa de losbuenos oficios à q confiefa el credito de fu facrificio, pronto à mas graves operaciones, en que conf-

(3.) tituirfe voto mas grato de V.R. fervicio:para que fucitan-

69. do las infinuaciones, ya cxpueftas avucftroSuPremocon- 
สำ (3) fo en dibujo deprecando à V.R. Soberania meta los Colo res de fu Gracia alu Hechuras que avnque fuPufilidad no re prefente al vivo fu Copia, protefta enVueftro feruicio con las pinceladas de fu rendimiento y lealrad, fino Vigorizar l. feme janza, realzar las obligaciones de muy reconocido, ala Mag. nificencia de V.M. Cuia Perfona Guarde Diosconla Exalraciō y Trofeos, quefu Corona y Mageftad,merece y le pedimos fus Leales y fervorofos Vafallos.

Confts de los Originales, que paran en los Prorocolos fitados,y de Teftimonio da do en la Villa de Bejsr, alos 7.dias del nues de Abril.de 1600 . Sacadosala letra de los Libros d: Acwerdo ante Antonio Blafquez, Fumiliar del Santo oficio de la Ynquificion, de la Cindad de LLeren y fu parrido, Efcribano $R$. del Numeruy Aiuntamiento de dicha Villa.y de los teftimontos prejentados en la Secree aria del confejode Yndias.
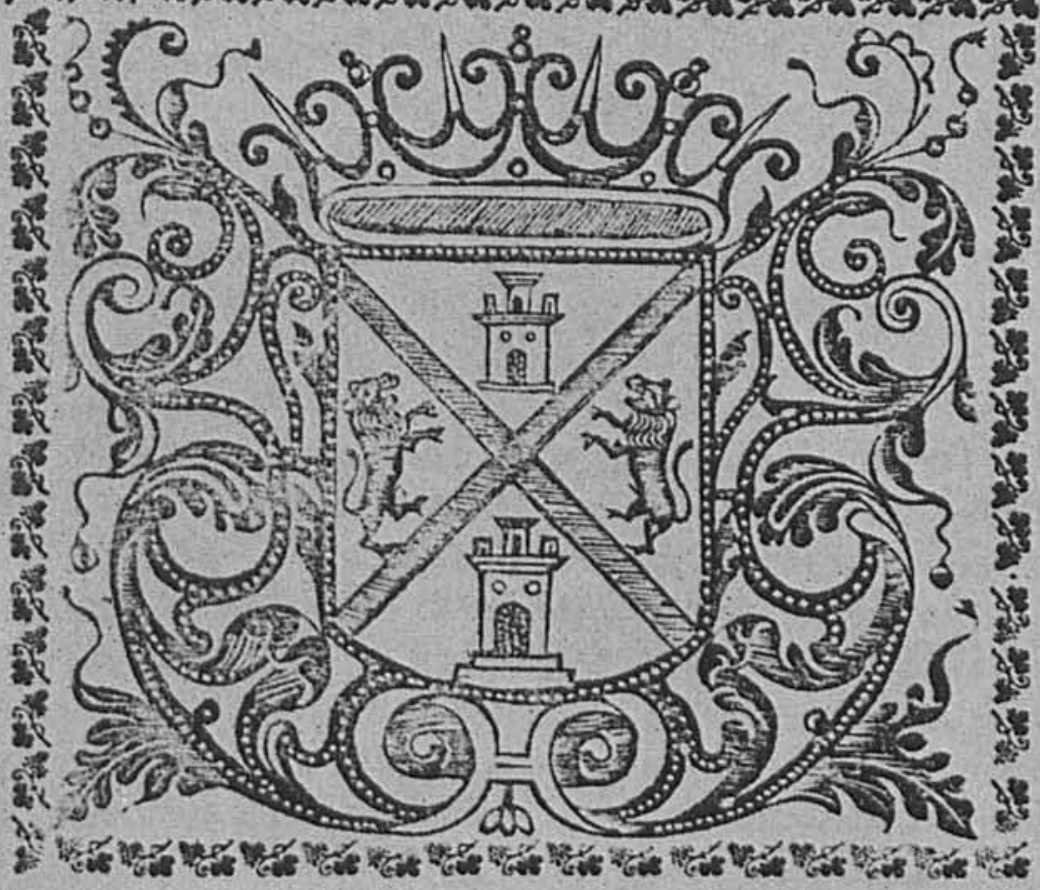
92. 6.:
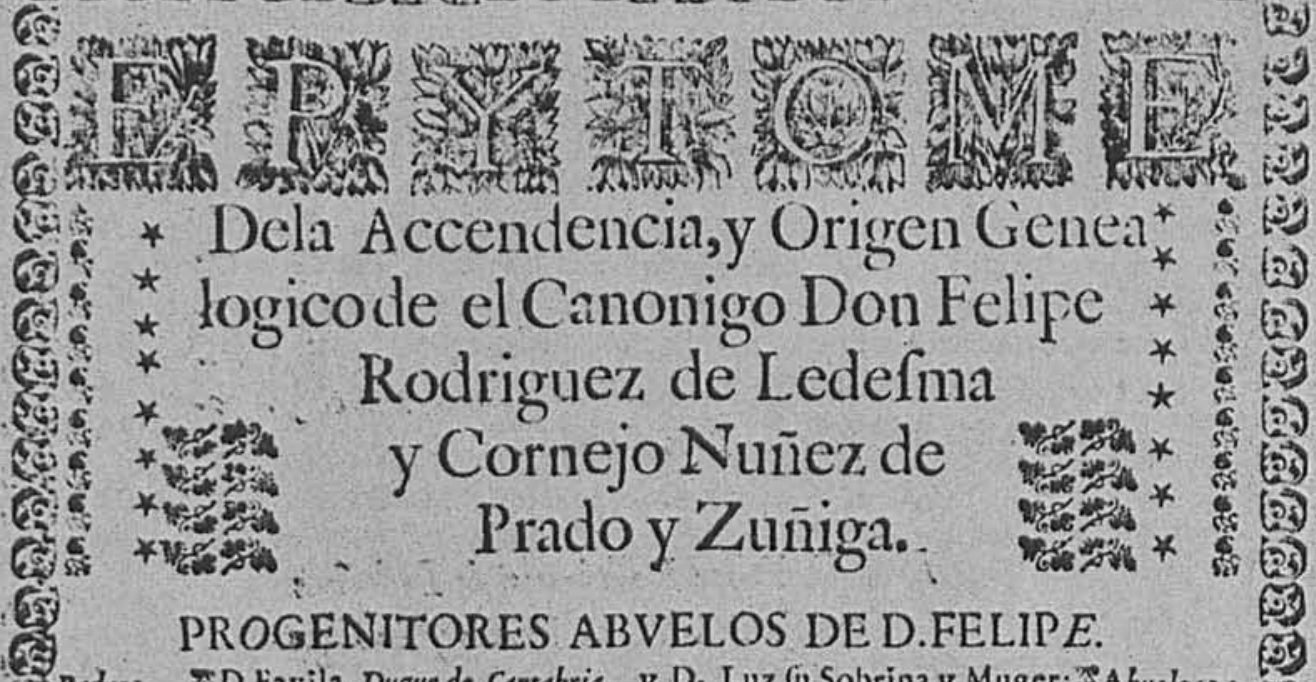

Sadres ED.Favila, Duque de Cantabria, y D. Luz fu Sobrina y Muge

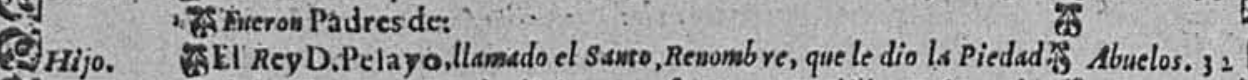

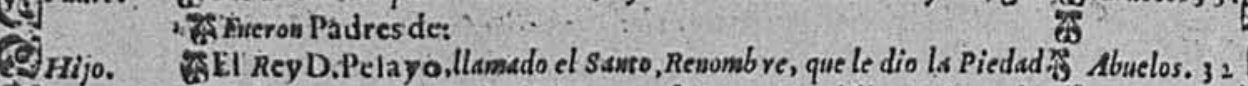
\%de los Coriftianos, que le eligierou por fu Rey $y$ Candillo, Reftaurad or Ey Fundador de la Monarquia E/pañola. Moyfes de la Ley de Gracia, , zFielprimero aquien fsle dio Tirulo de Don, que en aquel tiempo folo fe 6o daba à los Santos, Con el Patrocinio de Maria Santifsima. Nuefrsiós \&Señora.y al Siguo de nueftra Redempcion la Santa Cruz, que fe aparcio 3 Senel Cielod en el Ayre Veftids de Rejplandores de fuego con efras is Elerras, Y nhoc Signo Vinces. yacompañada de Coros Argelicos, que

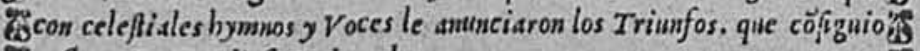
Teáó con D. Gaudiofa Padres de, 2D Hermenefềda, व̄cafocōD.Alonfo.L. el Catolico, Titulo ¿. 1 qu concedio elpapaZacarias.1.Padres de. WL Y rnfante D. V imarano, $\bar{q}$ cafo cö D.Berengucla:Padres de:

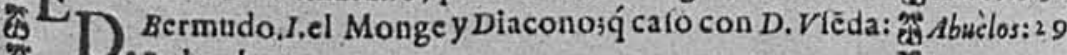
D. Padresde:

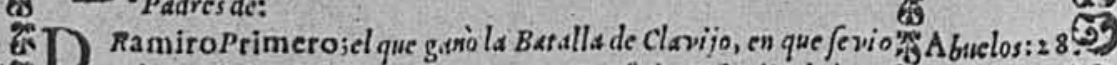
E. Delear el A pofol San Tiago, porque Fundo la Cofradia de la Ef 6 \$Spada, con treze Cusulleros calificados, que efcogiosla qual cl Papa. ? 6. A lexadro. III.A probo defpues por Orden Militar de San Tiago cuio ESSanro Cuerpo fe allo en Compoftelar; Reynando fu Tio y antecefor Don a EA A lanfo el Cafto: encuia Era Bernardo del carpio fu Sobrina, vencio la is EB Baralla de Ronces Valles: y dos Angeles le labraron la Cruz de oro 3 Qique oy efla en Sun Salusdor de Oviedo: y en fu tiempo fe eftablecio el *Condadode Caffillai y que los Señores Reyes pidan afus Vafallos, $y$ los 6.V afallos afus Reyes lo que felefdebiere por derecho en fuicio) $\dot{q}$ cafò $\%$ ẼcóD. Vrracapadres de. o Ordoño l el Primero,que entroenila Corona por fuccefios 
4ำ. .

[5 El numero de la linea que ocupa,qual yuiera perfona de eftas columnas da el gra

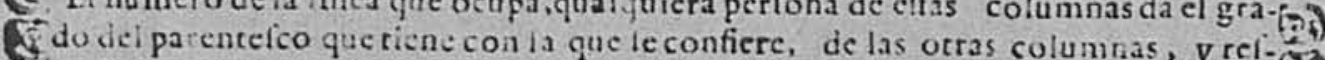
F. pecie Ae fu Pregenitor. La cenominacion de Primos da el aumero parale? Ho. La deTios ci aceendiente o fuperior, La de Sobrinos el decendiente o inferior, W. V. I uis Xl, es primo XII, del Scîor Emperador Carlos V. y de D.Iedro de Ledel-i⿹勹巳 Ce.ma y Paredes (llamado el fordo Virabuelo de Don Felipe de Ledeima) y es dicho 6i. D. PedrolobrinoX, de los Reyes Carholicos, y Tio Xll. del Señor Carlos II. ref. Ėipecto de la Señora Doña Berenguela de quien es Nieto XVI. Si fe confiere dentro de evna meima columna los que suceden la linea que ocupan, fon fus Nietos, menos el: inmediato, que es hijo, y los que anteceden la linea en que eftan,fon fus Abuelos, Sinenosel immediato, que es fu Padre, $y$ el grado fe conoce quitando al numero Eeten que fe halla el que ay defde el primero hafta el Abuelo,y contando para Nieto el

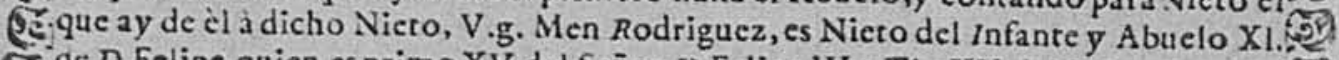
Eạj ac D.Felipe, quien es primo XV del Señor D.Felipe IV,y Tio XV.del Señor D.Carlos: (3) $11 . y$ dicho Señor Sobrino XV1. de dicho Don Felipe.

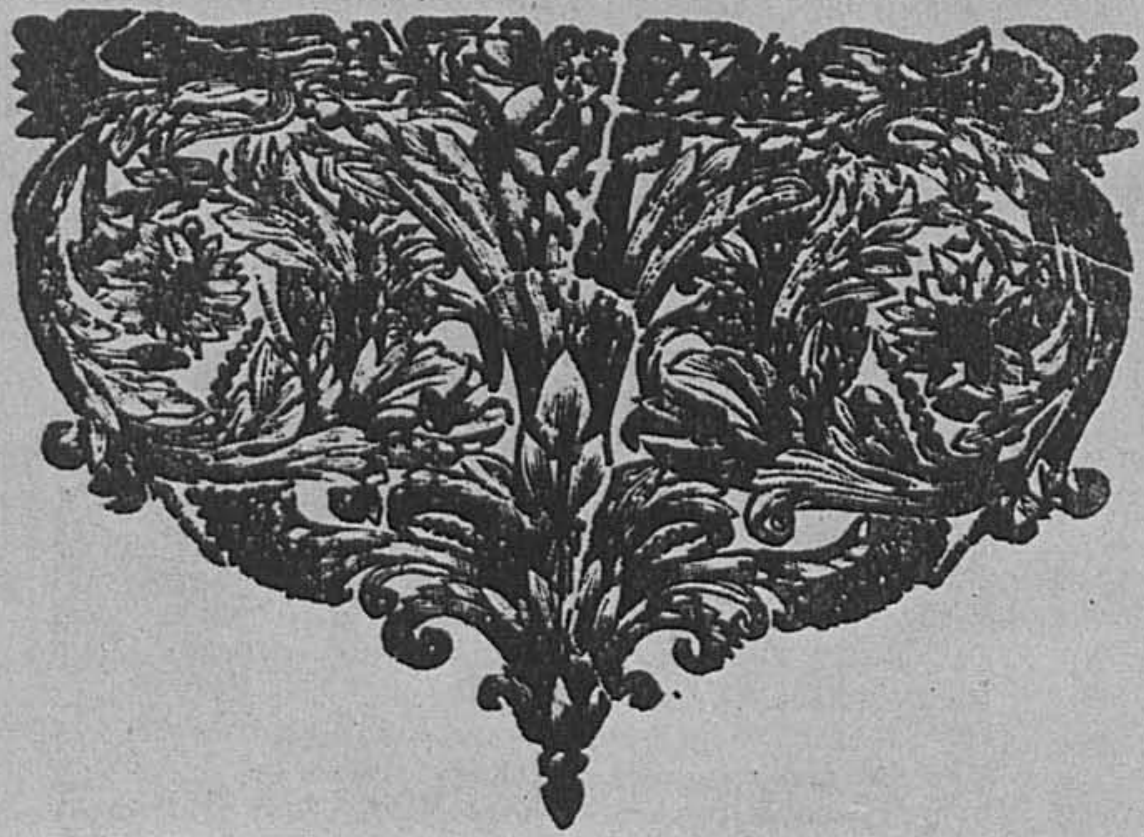




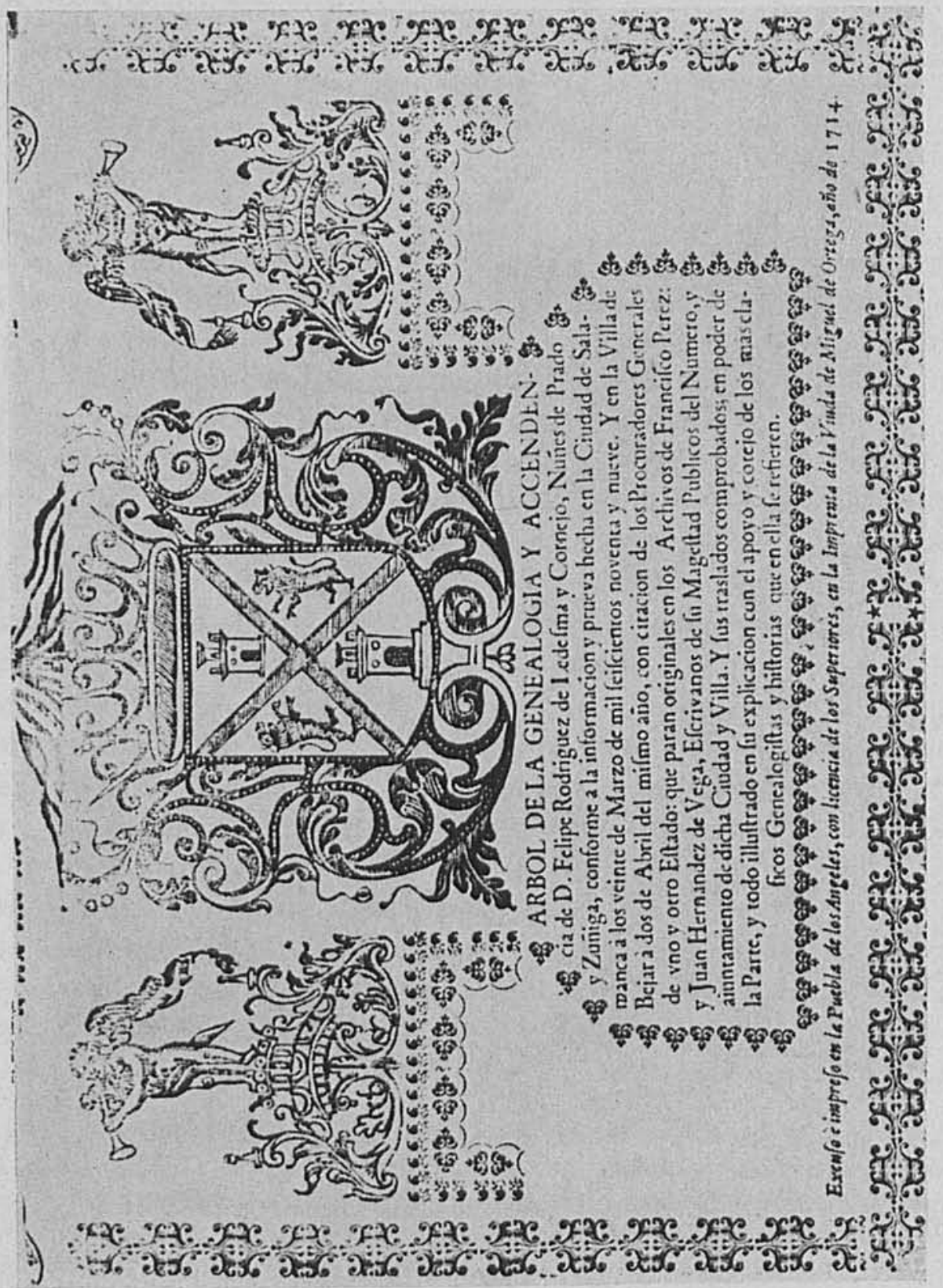


DOI: http://dx.doi.org/10.22201/iie.18703062e.1966.35.2446

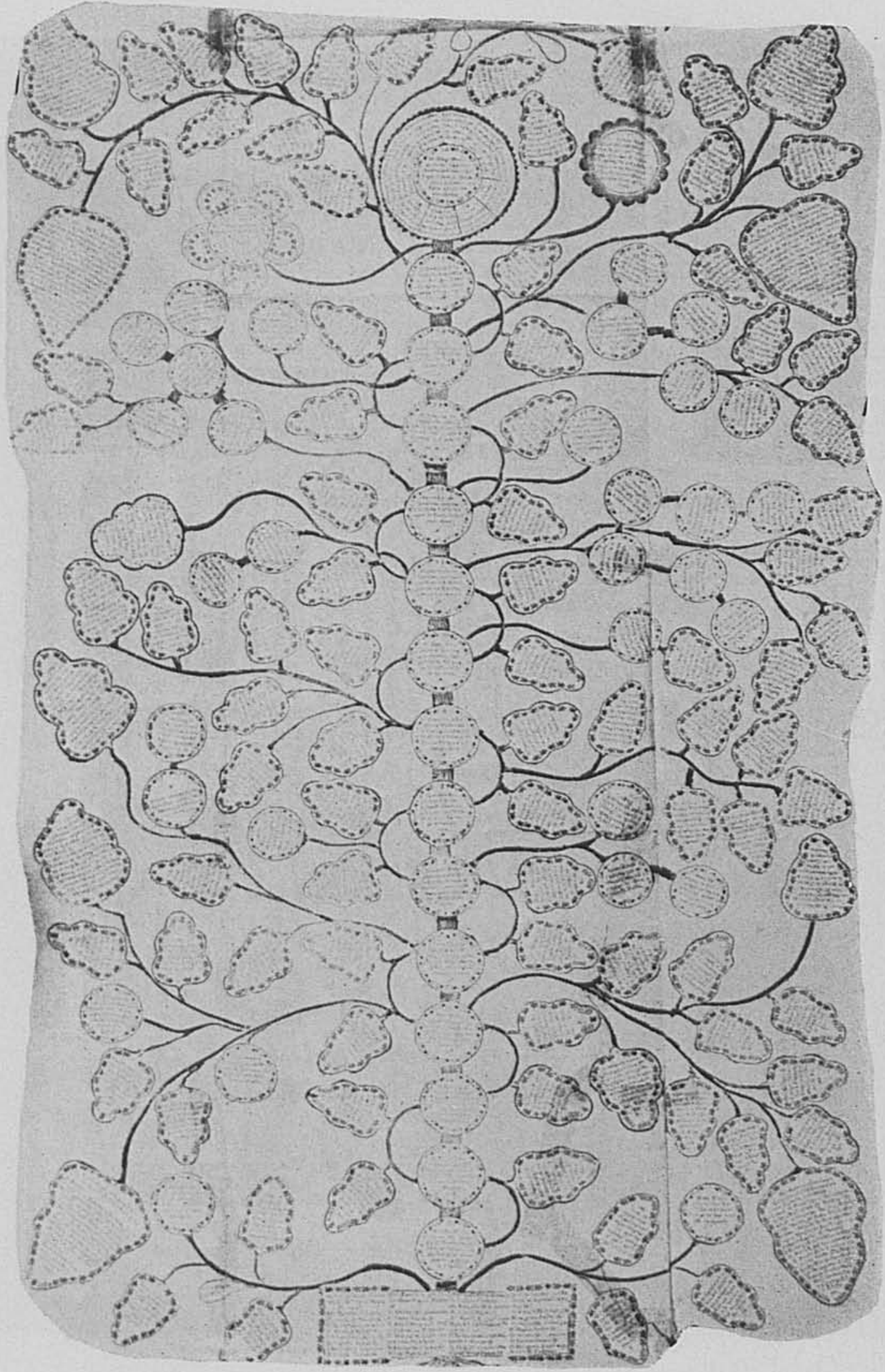


Prosigue en el folio 7 vta, el "Informe y Comprobación/Histórica de la Accedencia y/Arbol Genealógico, etcétera", que comprende hasta el folio 30 y a la vuelta termina. Al pie: "Con licencia en la Puebla: por la Viuda de Miguel Ortega. Año de 1714".

Miden los folios 29 centímetros y la parte impresa, 24.2 por 14 centímetros, aunque no con exactitud todos, como es natural.

Pero lo imponderable y único, es la hoja desplegada del árbol genealógico. Mide 88 centímetros de largo por 54 de ancho y está hecho con 6 planchas, tres grandes y tres chicas, de madera. El vigoroso árbol genealógico está dibujado, efectivamente, como un árbol con su tronco sustentante y sus hojas marginales, de varios tamaños.

¿Cómo fue hecha esta composición, alarde tipográfico increíble? Tuvo que ser de dos maneras: o las letras, una por una, se incrustaron en la madera, con un trabajo verdaderamente descomunal, o se vaciaron un tanto las hojas y los círculos del tronco del árbol genealógico y se rellenaron de lacre, goma o, más fácilmente, de cera, para colocar las letras y los adornos, una por una y uno por uno. ${ }^{3}$

La imprenta que se encargó de ejecutar esta magna obra tipográfica fue, como se ha dicho, la de la viuda de Ortega. Fue esta señora doña Manuela de la Ascensión Cerezo, esposa que había sido de Miguel de Ortega y Bonilla. Parece que éste comenzó con su imprenta en 1712 utilizando las viejas prensas de Fernández de León. ${ }^{4}$

Murió Ortega a fines de 1713 o principios de 1714, pues ese año empieza la imprenta con el nombre de su viuda y, valientemente, con este libro que damos a conocer. Los tipos habían sido renovados y variados, así como las viñetas y capitulares.

Fue doña Manuela Cerezo única impresora de Puebla desde 1714 hasta

3 En Defensa juridica por la Sra. Doña Maria Graciana de Velasco, Vivero y Peredo, Condesa del Valle de Orizaba (contra la demanda) puesta a posesión y propiedad de dicho condado por don Bernardino de Carbajal, Moctezuma, Vivero... y proseguida por el Sr. Don Juan de Carbajal, Moctezuma, Vivero, Duque de Linares y de Abran. tes... México. 1739, hay una hoja plegada con un árbol genealógico, pero muy inferior a éste.

4 José Toribio Medina, La Imprenta en la Puebla de los Angeles. MCMVIII, pp. xxxir a xxxv. José Miguel Quintana. Las artes gráficas en Puebla. Lib. Robredo. México, MCMLX, p. 18. 
1723, año en que ya tuvo un competidor, Francisco Xavier Morales. Continuó la viuda, sin embargo, con el mismo éxito, hasta 1758. Cua. renta y cuatro años de buena y meritoria labor tipográfica de la viuda más fecunda en impresiones. Decimos esto porque las viudas tuvieron un importante papel en la historia de la imprenta novohispana.

Y quede la vanidad de don Felipe Rodriguez de Ledesma satisfecha de que, gracias a ella, aún exhumemos su memoria por esta joya bibliográfica de Puebla. 